\title{
In Vivo Effects of 13-cis Retinoic Acid Treatment on the Concentration of Proteins and Lipids in Serum ${ }^{1}$ )
}

\author{
Göran A. Fex', Annika Aronsson ${ }^{2}$, Anders Andersson ${ }^{1}$, Kerstin Larsson ${ }^{1}$ and Peter Nilsson-Ehle ${ }^{1}$ \\ 1 Department of Clinical Chemistry \\ 2 Department of Dermatology \\ Lund University Hospital, Lund, Sweden
}

Summary: A number of serum components, whose concentrations or gene expression have been shown to be modulated by all-trans retinoic acid in vitro, were monitored in patients before and during treatment with Roaccuta$\mathrm{ne}^{\mathrm{TM}}$ (13-cis retinoic acid, 40-60 mg/day) for severe acne. The 13-cis retinoic acid concentration in serum rose from $5.25 \pm 1.09$ to $593 \pm 65 \mathrm{nmol} / 1$ (mean $\pm \mathrm{SD}$ ) $24 \mathrm{~h}$ after the latest dose. The concentration of all-trans retinoic acid in serum under Roaccutane ${ }^{\mathrm{TM}}$ treatment was measured in model experiments and shown to be $10-20 \mathrm{nmol} / \mathrm{l}$ i. e., 2-4 times the basal levels $(4.65 \pm 0.85 \mathrm{nmol} / \mathrm{l})$ when the 13-cis retinoic acid concentration was 370-980 $\mathrm{nmol} / \mathrm{l}$. The concentrations of creatine kinase-MB, apolipoprotein $\mathrm{B}$, total cholesterol and LDL cholesterol increased significantly while the other measured serum components, including lipoprotein lipase activity, were unaffected by Roaccutane ${ }^{\mathrm{TM}}$ treatment.

\section{Introduction}

Vitamin A or all-trans retinoic acid has been shown to influence the expression of several genes in vitro $(1-5)$. For example, all-trans retinoic acid concentration as low as $1 \mathrm{nmol} / \mathrm{l}(2)$ i.e. at concentrations well within the physiological concentration range $(4-6 \mathrm{nmol} / \mathrm{l})$ in serum $(6,7)$, increase the expression of the growth hormone gene by several orders of magnitude. In some cases a retinoic acid receptor response element has been demonstrated in the promoter region of the genes of induced proteins (5).

The administration of therapeutic doses of Roaccuta$\mathrm{ne}^{\mathrm{TM}}$ (13-cis retinoic acid) to humans (e.g. for the treatment of severe acne) increases not only the concentration of 13-cis retinoic acid, but also the concentration of all-trans retinoic acid, partly as a non-enzymatic process (10). 13-cis Retinoic acid does not bind to retinoic acid receptors and is probably inactive (9), while all-trans retinoic acid is the biologically active retinoid that binds to the retinoid receptors. As the half-life of all-trans retinoic acid is about $1 / 20$ of that of 13 -cis retinoid acid $(11,12)$, the relative concentration of all-trans retinoic acid in the tissues may be even higher than in serum.

All-trans retinoic acid has been shown to modify the expression of a number of genes in vitro $(1-5)$. To de-

\footnotetext{
1) Supported by grants from the Swedish Medical Research Council (Nos. 03364 and 04966), the Påhlsson Foundation, the Gyllenstierna Foundation, the Lunds Sjukvårdsdistrikt Fonder and the Medical Faculty, University of Lund.
}

termine whether these actions of vitamin A/all-trans retinoic acid are also demonstrable in vivo, we have measured the concentration of a number of serum components which are related to these genes.

\section{Materials and Methods}

Patients

The patients were 18 males aged 17-31 years and 2 females aged 28 and 47 years who were given Roaccutane ${ }^{\mathrm{TM}} 40$ or $60 \mathrm{mg} /$ daily as treatment for acne. Ten of the patients also received erythromycin to attenuate initial "flare up" symptoms. They were all subjectively healthy and were not taking any other medication. Serum 13-cis retinoic acid concentration was measured to ensure compliance. Blood was drawn in vacuum tubes without additions, before and after 6 weeks of treatment, as fasting morning samples, immediately before the intake of the daily dose of Roaccutane ${ }^{\mathrm{TM}}$ (i.e. $24 \mathrm{~h}$ after the last dose). Serum was recovered by centrifugation and stored in the dark at $-20^{\circ} \mathrm{C}$ until analysed.

During the course of the study we found that it was difficult to completely avoid exposure of the patient samples to light, which is known to facilitate isomerisation of 13-cis to all-trans retinoic acid (10). Therefore, the concentrations of all-trans retinoic acid in serum during Roaccutane ${ }^{\mathrm{TM}}$ treatment was estimated in separate experiments in which we measured the levels of 13-cis and alltrans retinoic acids in a volunteer at various times (4-24 h) after intake of $50 \mathrm{mg}$ Roaccutane ${ }^{\mathrm{TM}}$. These blood samples were collected in vacuum tubes without addition, immediately wrapped in aluminium foil to protect them from light, allowed to clot at room temperature and transferred to a refrigerated swing-out centrifuge. The resulting serum was handled in the dark or under yellow light. The results of these measurements were used as an cstimate of the true serum concentration of all-trans retinoic acid in patients on Roaccutane ${ }^{\mathrm{TM}}$ treatment.

Since all components could not be measured in all patients due to the limited amount of serum, each component was first ineasured in five randomly chosen patient samples. If there was a consistent difference $(P<0.05$ between the concentrations in sumples ob- 
tained before and during treatment) the same component was measured in 4-5 more patient sera. Some minor differences may be have been missed with this approach, but all consistent effects of Roaccutane $^{\mathrm{TM}}$ have probably been detected.

Methods

The all-trans and 13-cis retinoic acid preparations used as calibrators were gifts from Hoffman LaRoche, Basel. Acetonitrile and methanol were HPLC grade. All other chemicals were pa grade unless otherwise specified. Retinoic acids (all-trans and 13-cis) were determined using the HPLC system described by Wyss \& Bücheli (13).

Collagen type I telopeptide and procollagen type I propeptide were determined using a test kit from Orion (Turku, Finland) and intact parathyrin, calcitonin and osteocalcin with test kits from INCSTAR (Stillwater, MN, USA). Sex hormone-binding globulin and testosterone were determined by radioimmunoassay (with locally developed antibodies) using purified human sex hormone-binding globulin and pure testosterone as calibrators. Follitropin and lutropin were determined with Amerlite kits (Kodak Clinical Diagnostics, Amersham, UK) and somatotropin with a kit from Pharmacia (Uppsala, Sweden). Retinol-binding protein was determined using rocket electrophoresis with antibodies from DAKO (Copenhagen, Denmark) and a calibrator from Behringwerke AG (Marburg, Germany). Transthyretin and ceruloplasmin were determined turbidimetrically using antibodies from DAKO (Copenhagen, Denmark) and CRM 470-CAP-IFCC (Lot 91/06 19) as calibrator. Apolipoprotein A-I and apolipoprotein B were determined turbidimetrically using antibodies and calibrators from Roche (Basel, Switzerland) and lipoprotein(a) and $\beta_{2}$-microglobulin with antibodies and calibrators from DAKO (Copenhagen, Denmark). Alkaline phosphatase $^{2}$ ), creatine kinase ${ }^{2}$ ) isoenzyme $\mathrm{MB}$, triacylglycerol, cholesterol and HDL cholesterol were determined using an Ektachem 700 XRC. LDL cholesterol was calculated according to Friedewald et al. (14).

Lipoprotein lipase and hepatic lipase activities were determined in postheparin plasma (15) before and after 6 weeks of Roaccutane ${ }^{\mathrm{TM}}$ treatment. The protocol was approved by the local ethics committee. Data are given as mean $\pm S D$. The significance of differences was evaluated using Wilcoxon's signed rank test.

\section{Results}

The serum concentrations of all-trans and 13-cis retinoic acid in the patients before Roaccutane ${ }^{\mathrm{TM}}$ treatment was $4.65 \pm 0.85$ and $5.25 \pm 1.09 \mathrm{nmol} / 1(\mathrm{~N}=20)$ respectively. The reference intervals (derived from 80 blood donors, 40 males and 40 females $20-60$ years old) were $3.50-7.30$ and $2.60-8.20 \mathrm{nmol} / \mathrm{l}$ for all-trans and 13cis retinoic acid, respectively. The levels of all-trans and 13-cis retinoic acid in serum increased as a result of Roaccutane $^{\mathrm{TM}}$ treatment. The concentration of 13-cis retinoic acid in the patients (samples drawn $24 \mathrm{~h}$ after the latest dose) was $180-1800 \mathrm{nmol} / \mathrm{l}$ (mean $593 \mathrm{nmol} / \mathrm{l}$ ). The concentration of all-trans retinoic acid in serum (measured in model experiments only, see Methods section) was 2-3 percent of the concentration of 13-cis retinoic acid in the concentration range of $370-890$ $\mathrm{nmol} / \mathrm{l} 13-c i s$ retinoic acid. The concentrations of all-

2) Enzymes:

Creatine kinase (EC 2.7.3.2.)

Alkaline phosphatase (EC 3.1.3.1.) trans and 13-cis retinoic acid in serum in these model experiments were strongly correlated [all-trans retinoic acid $(\mathrm{nmol} / \mathrm{l})=0.021 \times(13-c i s$ retinoic acid $(\mathrm{nmol} / \mathrm{l})$ $+1.81 ; \mathrm{N}=8 ; \mathrm{r}=0.87 ; \mathrm{p}<0.001]$.

Inspection of the chromatograms showed that all samples contained substantial amounts of 4-oxo 13-cis and 4-oxo all-trans retinoic acid, which are the principal metabolites of all-trans and 13-cis retinoic acids in man $(6,7)$.

Table 1 lists a number of proteins, whose gene expression and synthesis in vitro has been shown to be influenced by vitamin A/all-trans retinoic acid (1-5). The only component which was affected in vivo during treatment with Roaccutane $^{\mathrm{TM}}$ was creatine kinase isoenzyme MB activity, the concentration of which increased significantly (tab. 1). In many cases the enzyme activity exceeded the upper reference limit of the laboratory, but it never reached the values seen in myocardial infarction.

The components in table 2 were determined because they are related to the components in table 1 . Of these variables, only the concentrations of cholesterol, LDLcholesterol and apolipoprotein B were increased as a result of Roaccutane ${ }^{\mathrm{TM}}$ treatment. Neither sex hormonebinding globulin, the gonadotropins, the collagenases, lipoprotein(a) nor the lipases were affected.

\section{Discussion}

The concentration of all-trans retinoic acid in serum during Roaccutane ${ }^{\mathrm{TM}}$ treatment can be estimated at 10$20 \mathrm{nmol} / \mathrm{l}$, which is about $2-4$ times the normal level. The half-life of all-trans retinoic acid in serum (11) is considerably shorter than that of 13-cis retinoic acid (12) ( $<1 \mathrm{~h}$, compared to $<17 \mathrm{~h}$ ). Thus, the relative increase in all-trans retinoic acid in the tissues may be even greater than 2-4 fold.

The components in table 2 were chosen because they are related to those in table 1 . Thus, sex hormone-binding globulin gene expression is stimulated by thyroid hormones (17) in vivo, and thyroid hormone receptors and the RXR series of retinoid receptors cooperate in regulating the expression of thyroid hormone-responsive genes (18). Somatotropin expression is regulated in vivo by all-trans retinoic acid (2) and follitropin and lutropin are, like somatotropin, pituitary gonadotropins. Since collagen type I synthesis has been shown to be increased by vitamin $\mathrm{A}$ (presumably all-trans retinoic acid) (19, 20) it seemed interesting to monitor both its synthesis (measured as procollagen type I C-terminal propeptide concentration in serum, tab. 1) and its degradation by collagenases (measured as collagen type I telopeptide, tab. 2).

Serum triacylglycerol and cholesterol concentrations have been shown to be elevated, in a dose-dependent 
way, in individuals taking Roaccutane ${ }^{\mathrm{TM}}(21)$. The cause is unknown. Therefore, we found it relevant (tab. 2) to determine triacylglycerol, total cholesterol, low density (LDL) and high density lipoprotein (HDL) cholesterol concentrations, the concentrations of apolipoprotein A-I (in tab. 1), apolipoprotein B, lipoprotein(a) and the activities of lipoprotein lipase and hepatic lipases. These lipases are major determinants of plasma lipoprotein concentrations and might be causally involved in the development of hypercholesterolaemia and triglyceridaemia during Roaccutane ${ }^{\mathrm{TM}}$ treatment. The triacylglycerol concentration in serum was not significantly increased in these patients (tab. 2), possibly because Roaccutane ${ }^{\mathrm{TM}}$ dose was relatively low (21), or because we missed the increase due to the design of the experiment.

The serum concentrations of total cholesterol, apolipoprotein $B$ and LDL cholesterol were significantly increased during Roaccutane ${ }^{\mathrm{TM}}$ treatment (tab. 2). Apolipoprotein A-I, lipoprotein(a) and HDL cholesterol (23) concentrations were unaltered (tab. 2). Postheparin lipoprotein lipase and hepatic lipase activities were not significantly changed (tab. 1), which is in accord with other studies $(23,24)$.

Experiments with primary cultures of primate liver cells have shown that the transcription of the apolipoprotein A-I gene is increased by retinoic acid while the expression of apolipoprotein B gene is unaffected (25). Other experiments with all-trans retinoic acid show that the expression of the apolipoprotein A-I gene is increased in HepG2 cells and decreased in primary rat liver cell cultures, and that the level of apolipoprotein A-I decreased in rat serum in vivo (26). We (tab. 2) and others (27) found that the serum concentration of apolipoprotein A-I is unchanged and that of apolipoprotein B is increased during Roaccutane ${ }^{\mathrm{TM}}$ treatment. The increase in serum LDL cholesterol (tab. 2) is in accord with previous studies (23) and is consistent with the increase in apolipoprotein B concentration.
Tab. 1 Serum components (compiled in l.c. (1)) whose concentration or gene expression has been shown to be affected by the administration of vitamin $A$ in vitro, before and after $>6$ weeks of Roaccutane $\mathrm{TM}^{\mathrm{TM}}(40-60 \mathrm{mg} / \mathrm{day})$ to young adults ( $18 \mathrm{males}$ and
2 females). Values are mean \pm SD. Expected direction of change: $\mathrm{D}=$ Decrease, $\mathrm{I}=$ Increase $)$. $(\mathrm{N}=5$ except for creatine kinaseMB isoenzyme, where $N=9$ ). The reference intervals refer to men and women $20-60$ years old.

\begin{tabular}{|c|c|c|c|c|c|}
\hline \multirow{3}{*}{$\begin{array}{l}\text { Component (Decrease/Increase) } \\
\text { Procollagen I propeptide (D) }\end{array}$} & \multirow{2}{*}{$\begin{array}{l}\text { Unit } \\
(\mu \mathrm{g} / \mathrm{l})\end{array}$} & Before treatment & $\begin{array}{l}\text { After }>6 \text { weeks } \\
\text { treatement }\end{array}$ & \multicolumn{2}{|c|}{ Reference interval } \\
\hline & & $200 \pm 72$ & $211 \pm 38$ & 40 & -200 \\
\hline & $(\mathrm{pmol} / \mathrm{l})$ & $2.0 \pm 0.9$ & $2.7 \pm 2.1$ & 1.0 & $-\quad 5.0$ \\
\hline Osteocalcin (bone Gla protein) (I) & $(\mu \mathrm{g} / 1)$ & $7.4 \pm 4.5$ & $6.5 \pm 3.2$ & 1.8 & -6.6 \\
\hline Calcitonin (D) & $(\mu \mathrm{g} / \mathrm{l})$ & $18.4 \pm 7.2$ & $18.6 \pm 8.0$ & & $<27$ \\
\hline Retinol-binding protein (I) & $(\mathrm{mg} / \mathrm{l})$ & $40 \pm 12$ & $47 \pm 17$ & 50 & -112 \\
\hline Transferrin (I) & $(\mathrm{g} / \mathrm{l})$ & $2.2 \pm 0.4$ & $2.4 \pm 0.2$ & 1.7 & $-\quad 2.7$ \\
\hline Transthyretin (I) & $(\mathrm{g} / 1)$ & $0.29 \pm 0.06$ & $0.30 \pm 0.07$ & 0.22 & 0.43 \\
\hline Ceruloplasmin (I) & $(\mathrm{g} / \mathrm{l})$ & $0.27 \pm$ & $0.29 \pm 0.03$ & 0.22 & $-\quad 0.42$ \\
\hline Growth hormone (I) & $(\mathrm{mIU} / \mathrm{l})$ & $2.48 \pm 4.88$ & $0.92 \pm 1.35$ & & $<12$ \\
\hline Apolipoprotein A-I (D) & $(\mathrm{g} / \mathrm{l})$ & $1.32 \pm$ & $1.27 \pm 0.28$ & 0.95 & $-\quad 2.05$ \\
\hline Alkaline phosphatase (D, I) & $(\mu \mathrm{kat} / \mathrm{l})$ & $3.2 \pm$ & $3.4 \pm 1.3$ & 0.8 & 4.6 \\
\hline Creatine kinase-MB isoenzyme (I) & $(\mu \mathrm{kat} / \mathrm{l})$ & $0.08 \pm$ & $0.11 \pm 0.06^{\mathrm{a}}$ & & 0.08 \\
\hline$\beta_{2}$-Microglobulin (I) & $(\mathrm{mg} / \mathrm{l})$ & $1.45 \pm 0.23$ & $1.53 \pm 0.23$ & 0.9 & 2.5 \\
\hline
\end{tabular}

a $0.025>\mathrm{p}>0.01$

Tab. 2 Serum components before and after $>6$ weeks of Roaccutane $^{\mathrm{TM}}$ (40-60 mg/day) to young adults, (18 males and $2 \mathrm{fe}-$ males). Values are mean $\pm S D$. $(N=5$ except for apolipoprotein
$B$, where $N=9$ and lipoprotein lipase and hepatic lipase, $N=16$ ). The reference intervals refer to men and women $20-60$ years old.

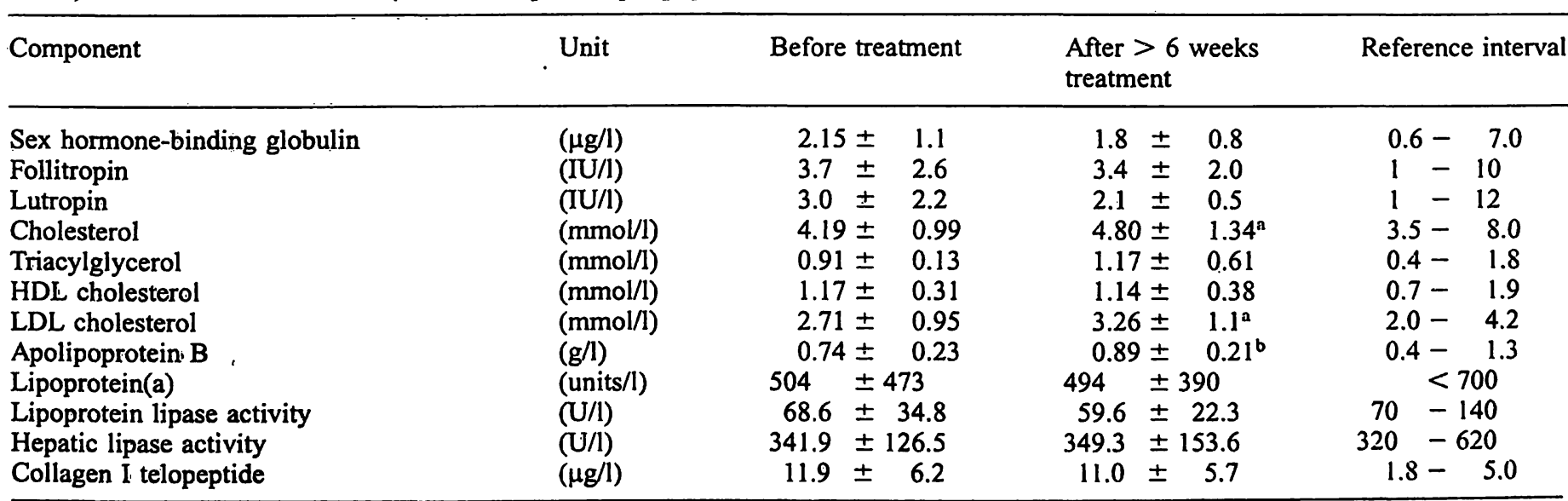

a $0.025>p>0.01 \quad$ b $p<0.01$ 
The effect of all-trans retinoic acid on the concentration of apolipoprotein $B$, therefore does not seem to be direct (25). Increased levels of apolipoprotein B may result from decreased clearance of apolipoprotein B-containing lipoproteins, e.g. through decreased LDL-receptor activity or from an increase in the production rate of the triacylglycerol-rich apolipoprotein B-containing lipoproteins. Apparently, decreased lipoprotein lipase or hepatic lipase activities are not involved (tab. 2).

The reasons for the discrepancy between the present in vivo data and the in vitro observations $(1-5)$, i. e. the lack of change in serum concentrations of some of the components listed in table 1 , is not known. Obviously, plasma concentrations result from the net contributions of synthesis, distribution and elimination, each of which may be the principal determinant of the actual plasma

\section{References}

1. Chytil F, ul-Haq R. Vitamin A mediated gene expression. Crit Rev Eukaryotic Gene Expression 1990; 1:61-73.

2. Bedo G, Santisteban P, Aranda A. Retinoic acid regulates growth hormone gene expression. Nature 1989; 339:231-4.

3. Oliva A, Dalla Raggione F, Fratta M, Marrone G, Palumbo R, Zappia V. Effect of retinoic acid on osteocalcin gene expression in human osteoblasts. Biochem Biophys Res Comm 1993; 191:908-14.

4. Hsu S-L, Lin Y-F, Chou C-K. Transcriptional regulation of transferrin and albumin genes by retinoic acid in human hepatoma cell line Hep 3B. Biochem J 1992; 283:611-5.

5. Rottman JN, Widom RL, Nadal-Girard B, Mahdavi V, Karathansis SK. A retinoic acid-responsive element in the apolipoprotein A I gene distinguishes between two different retinoic acid response pathways. Mol Cell Biol 1991; 11:3814-20.

6. Tang G, Russell RM. Formation of all-trans retinoic acid and 13-cis retinoic acid from all-trans retinyl palmitate in humans. J Nutr Biochem 1991; 2:210-3.

7. Eckhoff C, Collins MD, Nau H. Human plasma all-trans, 13cis and 13-cis 4-oxo retinoic acid profiles during subchronic vitamin A supplementation: comparison to retinol and retinol ester plasma levels. J Nutr 1990; 121:1016-25.

8. Creech Kraft J, Eckhoff C, Kochhar DM, Bochert G, Chaoud I, Nau H. Isotretinoin (13-cis retinoic acid) metabolism, cistrans isomerisation, glucuronidation and transfer to the mouse embryo: consequences for teratogenicity. Teratogenesis, Carcinogenesis and Mutagenesis 1991; 11:21-30.

9. Lewin AA, Bosakowski T, Kazmer S, Grippo JF. 13-cis retinoic acid does not bind to the retinoic acid receptors alpha, beta and gamma [abstract 648]. Toxicologist 1992; 12:181.

10. Shih TW, Shealy YF, Strother DL, Hill DL. Non-enzymatic isomerization of all-trans and 13-cis retinoids catalyzed by sulfhydryl groups. Drug Metab Dispos 1986; 14:698-702.

11. Warrell RP. Clinical pharmacology of oral all-trans retinoic acid in patients with acute promyelocytic leukemia. Cancer Res 1992; 52:2138-42.

12. Brazzell RK, Vane FM, Ehmann CW, Colburn WA. Pharmacokinetics of isotretinoin during repetitive dosing to patients. Eur J Clin Pharmacol 1983; 24:685-702.

13. Wyss R, Bücheli F. Quantitative analysis of retinoids in biological fluids by high-performance liquid chromatography using column switching. I. Determination of isotretinoin and tretinoin and their 4-oxo metabolites in plasma. J. Cromatogr 1988; 424:303-14. concentration; thus, the impact of synthesis is not necessarily decisive for plasma levels. However, it is also possible that the elevation of the concentration of all-trans retinoic acid, the active retinoid, in serum to only $2-4$ times the normal level, was too small, and that the concentrations of all-trans retinoic acid in the relevant tissues (e.g. the liver) was insufficient to increase retinoic acid receptor occupancy, so that transcription of the genes in question was unaffected. Possibly, the all-trans retinoic acid is sequestered in the tissues by protein binding (e.g. to cellular retinoic acid binding proteins, CRABPs, which are actually induced by all-trans retinoic acid (28)) and is therefore unavailable to the receptors. Finally, it cannot be excluded that 14-hydroxy-retro retinol (30) rather than all-trans retinoic acid is responsible for many of the effects of vitamin A reported (1).

14. Friedewald WT, Levy RI, Fredrickson DS. Estimation of the concentration of low density lipoprotein cholesterol without use of the preparative ultracentrifuge. Clin Chem 2972; 18:499-506.

15. Nilsson-Ehle P, Ekman R. Rapid, simple and specific assays for lipoprotein lipase and hepatic lipase. Artery 1977; 3:194-209.

16. Adamson ED, Evans MJ, Magrane GG. Biochemical markers of the progress of differentiation in cloned teratocarcinoma cells. Eur J Biochem 1977; 79:607-15.

17. Raggatt LE, Blok RB, Hamblin PS, Barlow JW. Effects of thyroid hormones on sex hormone-binding globulin gene expression in human cells. J Clin Endocrinol Metab 1992; 75:116-20.

18. Yu VC, Delsert C, Andersen B, Holloway JM, Devaaru OV, Naar AM, et al. A coregulator that enhances binding of retinoic acid, thyroid hormone and vitamin $\mathrm{D}$ receptors to their cognate response elements. Cell 1991; 76:1251-66.

19. Davis BH, Pratt BM, Madri JA. Retinol and extracellular collagen matrices modulate hepatic ito cell collagen phenotype and cellular retinol-binding protein. J Biol Chem 1987; 262:10280-6.

20. Otha A, Uitton J. Procollagen gene expression by scleroderma fibroblasts in culture. Arthrit Rheumat 1987; 30:404-10.

21. Marsden JR. Lipid metabolism and retinoid theraphy. Pharmacological Ther 1989; 40:55-65.

22. Laker MF, Green C, Buyihan AKMJ, Shuster S. Isotretinoin and serum lipids: studies on fatty acid, apolipoprotein and intermediary metabolism. Brit J Dermatol 1987; 117:203-6.

23. Vahlquist C, Michaelsson G, Vahlquist A, Vessby B. Sequential comparison of etretinate (Tigason) and isotretinoin (Roaccutane $^{\mathrm{TM}}$ ) with special regard to their effect on serum lipoproteins. Brit J Dermatol 1985; 112:69-75.

24. van Der Schoeff JG, Jansen H. Postheparin lipolytic activity and in vitro lipolysis of serum triglycerides during treatment with isotretinoin. In: Saurat J, editor. Retinoids: new trends in research and theraphy. Basle: Karger, 1985:466-71.

25. Kaptein A, de Wit EC, Princen HM. Retinoids stimulate apo A I synthesis by induction of gene transcription in primary hepatocyte cultures from cynomolgus monkey (Macaca fascicularis). Arteriosclerosis Thrombosis 1993; 13:1505-14.

26. Berthou L, Staels B, Saldicco I, Berthelot K, Casey J, Fruchart $\mathrm{J}-\mathrm{C}$, Denefle $\mathrm{P}$, Branellec D. Opposite in vitro and in vivo regulation of hepatic apolipoprotein A I gene expression by retinoid acid. Atherosclerosis Thrombosis 1994; 14:1657-64.

27. Marsden JR. Effects of dietary fish oil on hyperlipemia due to isotretinoin and etretinate. Human Toxicol 1987; 6:219-22. 
28. Ong DE, Newcomer ME, Chytil F. Cellular retinoid-binding protcins. In: Sporn MB, Roberts AB, Goodman DS, editors. The retinoids. Biology chemistry and medicine. $2 n$ ed., New York: Raven Press, 1994:283-318.

29. Boylan JF, Gudas L. Overexpression of cellular retinoic acid binding protein-l (RABP-I) results in reduction in differentiation-specific gene expression in $\mathrm{F} 9$ teratocarcinoma cells. $\mathrm{J}$ Biol Chem 1991; 112:965-79.
30. Buck J, Derguini F, Levi E, Nakanishi K, Hämmerling U. Intracellular signalling by 14 hydroxy-4,4-retro-retinol. Science 1991; 254:1654-6.

Received July 6/September 18, 1995

Corresponding author: Göran Fex, MD, PhD, Department of Clinical Chemistry, Lund University Hospital, S-22185 Lund, Sweden 
